\title{
Radon, gamma-ray exposure and natural radionuclides
}

\author{
By P. Wanabongse ${ }^{1, *}, \mathrm{~W}$. Thorarit ${ }^{1}, \mathrm{~N}$. Yimchalam $^{1}$ and S. Bovornkitti ${ }^{2}$ \\ 1 Thailand Institute of Nuclear Technology, Ongkarak, Nakon Nayok, Thailand \\ 2 The Royal Institute, Dusit, Bangkok, Thailand
}

(Received November 27, 2009; accepted in revised form December 11, 2010)

\begin{abstract}
Thailand / Lung cancer incidence / Residential radon / Gamma-ray exposure / Activity concentration / Naturally occurring radionuclides
\end{abstract}

\begin{abstract}
Summary. Measurements were conducted to determine residential radon exposure levels in provinces with high lung cancer incidence in three different regions of Thailand. The measurements revealed that the average indoor radon levels were $20.0,24.4$, and $13.1 \mathrm{~Bq} \mathrm{~m}^{-3}$, and that the average gamma dose rates were 145,164 , and $54 \mathrm{nSvh}^{-1}$ in Chiangmai, Songkhla and Khonkaen provinces, respectively. The spectroscopic analysis of soil samples collected from the three provinces showed that the highest contents of Ra-226, Th232, and K-40 were present in Songkhla, with values of 93.7, 71.9, and $786.9 \mathrm{~Bq} \mathrm{~kg}^{-1}$, respectively, and the lowest contents were present in Khonkaen, with values of 15.6, 19.0, and $46.8 \mathrm{~Bq} \mathrm{~kg}^{-1}$, respectively. The results of our analysis of the activity concentrations of naturally occurring radionuclides helped explain the lower levels of radon gas and gamma-ray exposure in Khonkaen.
\end{abstract}

\section{Background and rationale}

To verify the association between residential radon exposure and lung cancer incidence, we measured radon gas levels in the houses of proven cancer patients as cases and in nearby houses as controls [1-3]. The measurements were conducted in three provinces in different regions of Thailand, namely Chiangmai in the north, Khonkaen in the northeast and Songkhla in the south (see Fig. 1). Gamma-ray exposure was also measured at each house. The radon levels in all houses visited did not exceed the tentatively accepted safe level in Thailand of $148 \mathrm{~Bq} \mathrm{~m}^{-3}$. Gamma-ray exposure at each house was also found to be on a normal environmental level. Therefore, it was concluded that radon gas exposure in such low-level ranges would unlikely be the cause of lung cancer or have benefits through hormesis (such as radon spa). However, we noted that the average indoor radon and gamma-ray exposure levels in Khonkaen were much lower than those in the other two provinces. These features were generally found in all of the houses visited. The lower level of radon could be the result of lower contents of Ra-226 in the building materials, in the soil under the foundation of a house, and in the rock and soil in the surrounding area.

\footnotetext{
*Author for correspondence (E-mail: paiwann@ @otmail.com).
}

The lower level of gamma-ray exposure could be the result of lower contents of naturally occurring radionuclides in the environment. We proceeded to identify the reason behind such phenomena.

\section{Methodology}

\subsection{Materials}

During June to September, 2008, a total of 56 case and control houses in Chiangmai, 60 case and control houses in Songkhla, and 62 case and control houses in Khonkaen were surveyed. During October to December, 2008, soil samples were collected from Songkhla, Chiangmai and Khonkaen.

\subsection{Methods}

Indoor radon concentrations in the houses of known cancer cases and in the control houses were measured using pulsecounting ionization chambers (ATMOS $12 \mathrm{dpx}$ radon gas monitor, Gammadata Matteknik, Sweden). The instruments had been certified for radon measurement by the Swedish Radiation Protection Authority. Altogether, five monitors were alternately used among all visited houses. The measurement was performed in a closed bedroom for $30 \mathrm{~min}$.

Environmental gamma-ray exposure was measured using a sodium iodide scintillation survey meter manufactured by Ludlum Measurements, Inc., USA. The gamma-ray dose rate meter had been certified by the Secondary Standard Dosimetry Laboratory, Office of Atoms for Peace, Thailand. Measurements were at a height of approximately one meter above the floor or ground, inside and outside of a house.

Soil sample was collected at a depth of approximately 60 centimeters below ground level. The samples were dried in an oven at $105^{\circ} \mathrm{C}$, ground and sieved. Then the samples were put in measuring jars, sealed and kept for one month before the measurements were performed (see Fig. 2). The measurement time of the gamma-ray spectrometer (equipped with a hyper-pure germanium detector) for each sample was $80000 \mathrm{~s}$. Naturally occurring radionuclides in soil samples were analyzed. Photopeak energies of 609, 911 , and $1460 \mathrm{keV}$ were specified for the analysis of Ra-226, Th-232, and K-40, respectively. The quantitative determinations were performed against the reference material SRM 315 Marine Sediment, which was supplied by the International Atomic Energy Agency (IAEA). 


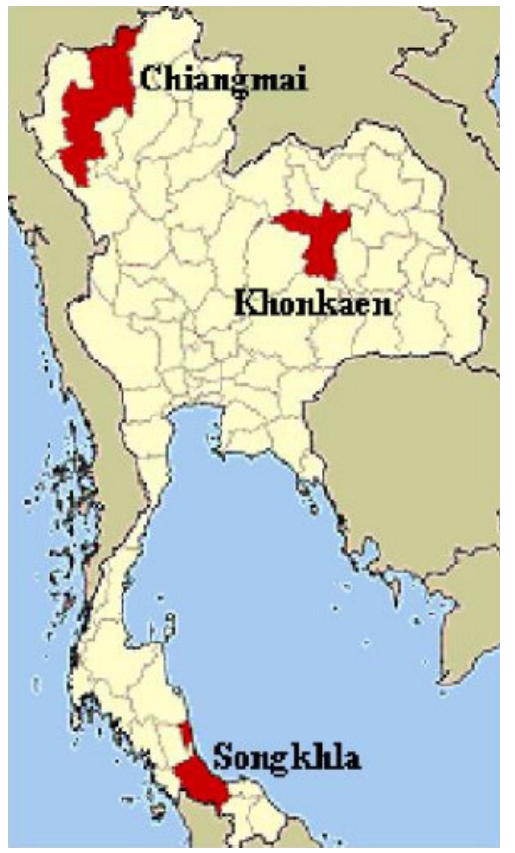

Fig. 1. Three surveyed provinces in Thailand.

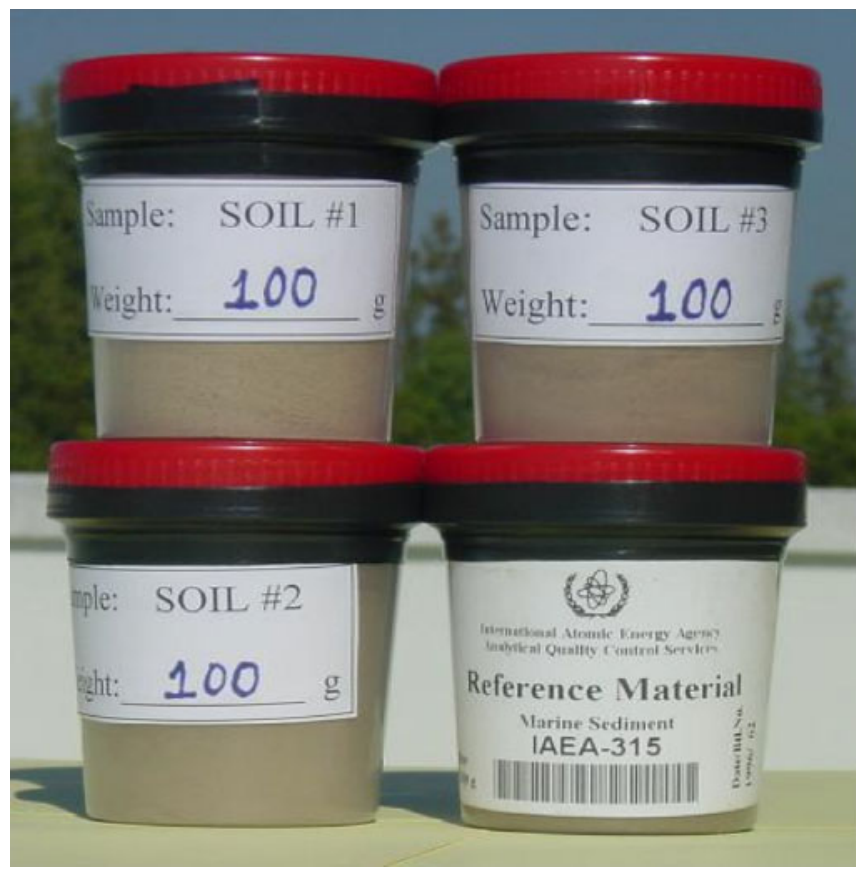

Fig. 2. Soil samples and the IAEA reference material.

\section{Results}

Three provinces in Thailand were visited for on-site measurements of radon gas and gamma-ray exposure. A total of 28,30 , and 31 pairs of case and control houses were included for the Chiangmai, Songkhla and Khonkaen provinces, respectively. Because the statistical analysis showed insignificant differences between all data of cases and controls, the case and control data were then pooled, and the means and standard errors were determined (Table 1). From the gamma spectroscopic analysis of soil samples, the contents of Ra-226, Th-232, and K-40 are shown in Table 2. Total potassium contents in soil samples calculated from
Table 1. Indoor radon and gamma-ray exposure.

\begin{tabular}{lcc}
\hline $\begin{array}{l}\text { Province } \\
\text { \# houses) }\end{array}$ & $\begin{array}{c}\text { Indoor radon } \\
\left(\mathrm{Bq} \mathrm{m}^{-3}\right)\end{array}$ & $\begin{array}{c}\text { Gamma-ray exposure } \\
\left(\mathrm{nSv} \mathrm{h}^{-1}\right)\end{array}$ \\
\hline $\begin{array}{l}\text { Chiangmai (56) } \\
\text { Range }\end{array}$ & $5-109$ & $50-280$ \\
Average & $20.3( \pm 14.6)$ & $145( \pm 51)$ \\
\hline $\begin{array}{l}\text { Songkhla (60) } \\
\text { Range }\end{array}$ & $5-73$ & $70-260$ \\
Average & $24.4( \pm 14.4)$ & $164( \pm 34)$ \\
\hline Khonkaen $(62)$ & & \\
Range & & $20-100$ \\
Average & $5-37$ & $54( \pm 17)$ \\
\hline
\end{tabular}

Table 2. Naturally occurring radionuclides in soil samples.

\begin{tabular}{lccc}
\hline Province & $\begin{array}{c}\mathrm{Ra}-226 \\
\left(\mathrm{~Bq} \mathrm{~kg}^{-1}\right)\end{array}$ & $\begin{array}{c}\mathrm{Th}-232 \\
\left(\mathrm{~Bq} \mathrm{~kg}^{-1}\right)\end{array}$ & $\begin{array}{c}\mathrm{K}-40 \\
\left(\mathrm{~Bq} \mathrm{~kg}^{-1}\right)\end{array}$ \\
\hline Chiangmai & $\begin{array}{c}73.0 \\
( \pm 4.9)\end{array}$ & $\begin{array}{c}67.7 \\
( \pm 4.8)\end{array}$ & $\begin{array}{c}279.1 \\
( \pm 9.2)\end{array}$ \\
\hline Songkhla & $\begin{array}{c}93.7 \\
( \pm 6.2)\end{array}$ & $\begin{array}{c}71.9 \\
( \pm 5.2)\end{array}$ & $\begin{array}{c}786.9 \\
( \pm 23.1)\end{array}$ \\
\hline Khonkaen & $\begin{array}{c}15.6 \\
( \pm 1.1)\end{array}$ & $\begin{array}{c}19.0 \\
( \pm 1.5)\end{array}$ & $\begin{array}{c}46.8 \\
( \pm 2.0)\end{array}$ \\
\hline
\end{tabular}

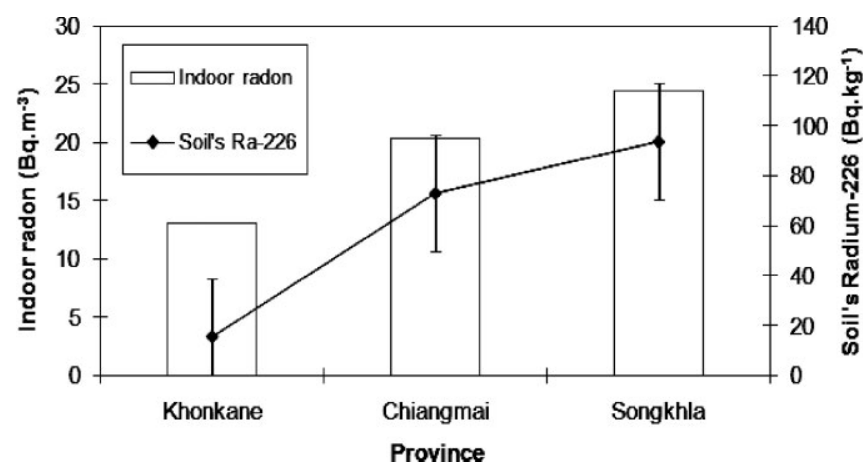

Fig. 3. Correlation between indoor radon level and Ra-226 content in soil sample.

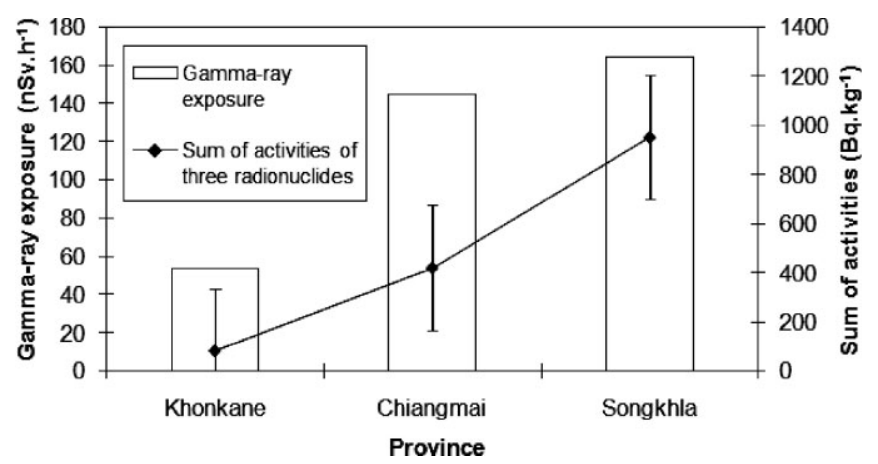

Fig. 4. Correlation between gamma-ray exposure and the sum of activities of the three radionuclides.

the amounts of $\mathrm{K}-40$ were found to be $0.1,0.9$, and $2.5 \%$ by weight for the Khonkaen, Chiangmai, and Songkhla provinces, respectively. 
Among the three provinces, the correlation between indoor radon level and Ra-226 content in soil sample is shown in Fig. 3, and the correlation between gamma-ray exposure and the sum of activities of the three radionuclides (Ra-226, Th-232, and K-40) is shown in Fig. 4.

\section{Discussion}

Residential radon levels were higher in the Songkhla and Chiangmai provinces but lower in Khonkaen. This difference can be explained by the differing Ra-226 contents in the soil samples, which were higher in the Songkhla and Chiangmai provinces but lower in Khonkaen. Higher levels of gamma-ray exposure were found in the Songkhla and Chiangmai provinces, whereas the lower levels were found in Khonkaen. This difference can be explained by the differing Ra-226, Th-232, and K-40 contents in the soil samples, which were higher in the Songkhla and Chiangmai provinces but lower in Khonkaen.

Of note, the Khonkaen province is located in the northeastern plateau region of Thailand. In this area, sandstone mountain ranges are the dominant scenery in many places. Soils are sandier and usually poor in nutrients and waterholding capacity, resulting in many dry lands with poor agricultural products. Potassium is an essential nutrient for plant growth and crop production, but its typical total content of only $0.1 \%$ at Khonkaen is too low.

\section{Conclusions}

The study of residential radon gas levels and gamma-ray exposures in correlation with lung cancer incidence in three provinces in different regions of Thailand yielded non- indicative results, but this study revealed distinctly different data for Khonkaen and the other two provinces. Although the analysis of naturally occurring radionuclides in soil samples by gamma-ray spectrometry suggested a possible explanation for such differences, it was quite interesting that the simple radon gas and gamma-ray exposure measurements led us to the findings.

To investigate the effect of radon gas on lung cancer incidence and the potassium content in soil for agricultural purposes, further study on radon gas, gamma-ray exposure, and naturally occurring radionuclides in other provinces of Thailand is encouraged. The use of environmental-level radiation survey meters for gamma-ray exposure measurements had been proven to be an efficient and effective tool, as in this study and in others $[4,5]$. We strongly recommended the use of this tool in any subsequent study.

\section{References}

1. Boonyaprapa, S., Wanabongse, P., Cheepsattayakorn, A., Saeung, S., Sola, B., Bovornkitti, S.: Residential radon exposure and lung cancer: a survey in Chiangmai Province. J. Health Sys. Res. 2, 460 (2008).

2. Moontep, C., Suparom, K., Sola, B., Chantarachote, W., Wanabongse, P., Bovornkitti, S.: Residential radon exposure and lung cancer: a survey in Khonkaen Province. Thammasat Med. J. 8, 455 (2008).

3. Bovornkitti, S., Pramphapar, T., Wanabongse, P., Sola, B.: Residential radon exposure and lung cancer: a survey in Songkhla Province. J. Roy. Inst. Thai. 34, 324 (2009).

4. Beaman, M., Tissot, P., Brandt, J.: Kopplin Gamma Radiation Survey, CBI Technical Report \# 01-001, Conrad Blucher Institute for Surveying and Sciences, Corpus Christi, Texas, USA (2001).

5. Ramli, A. T., Apriantoro, N. H., Wagiran, H.: Assessment of radiation dose rates in the high terrestrial gamma radiation area of Selama District, Perak, Malaysia. Appl. Physics Res. 1(2), 45 (2009). 